\title{
Desenvolvimento de produtos de moda para o público da terceira idade a partir de ferramentas do design participativo
}

\section{Fashion products development aimed to the senior population using participatory design tools}

CHEVA, Ana Flávia

Faculdade de Tecnologia SENAI Curitiba I an_31_@hotmail.com

LUGLI, Daniele Moraes

Universidade Federal do Paraná - UFPR I daniele.lugli@sistemafiep.org.br

\begin{abstract}
Resumo
O número de idosos é crescente no mundo, porém, pouco se fala a respeito da moda para a terceira idade, muitas vezes estereotipada por concepções do século passado. O presente estudo apresenta uma coleção de produtos de moda especialmente voltada a esse público a partir do conceito de design participativo, com ferramentas adaptadas ao processo de aceitação de tendências e na criação das peças. O processo aponta que o público é, na verdade, aberto a novas experiências e está disposto a conhecer novos produtos.

\section{Abstract}

The number of people over sixty years old is rising worldwide. However, little is discussed about fashion and garments for the senior population, often stereotyped by old-fashioned social stigmas. Thus, this study presents a collection of fashion products specially developed for this audience, based on the concept of participatory design adapted to the process of accepting trends and to the garment design. The process reveals that elderly people are, indeed, open to new experiences and willing to learn about new products.
\end{abstract}

Palavras-chave: Design Participativo. Co-design. Terceira idade. Produto de moda.

Keywords: Participatory design. Co-design. Seniors. Fashion product. 


\section{INTRODUĈ̣̃O}

A cada ano o número de idosos aumenta de maneira significativa. Segundo dados da Secretaria de Direitos Humanos (SDH) atualmente 1 em cada 9 pessoas no mundo tem mais de 60 anos e estima-se que até 2050 ocorra um crescimento para 1 em cada 5 pessoas, fazendo com que, pela primeira vez, haja mais idosos que crianças menores de 15 anos. Ou seja, serão 2 bilhões de idosos, ou $22 \%$ da população global. Esses dados se devem ao fato de que as pessoas estão tendo menos filhos, mas também porque a expectativa de vida da população está aumentando cada vez mais (BRASIL, 2016).

Ao contrário do que ocorria há décadas atrás, hoje essas pessoas são fisicamente e socialmente ativas. Entretanto, no Brasil pouco se fala a respeito da moda para essa parcela da população. Existem lojas rotuladas para terceira idade que oferecem tecnologia assistiva - acessórios como andadores e bengalas, ou mesmo peças que na verdade são como pijamas, roupas básicas com alguma abertura diferente que utilize velcro ou botões de pressão. Tal oferta não representa a terceira idade de hoje, pessoas ativas, que socializamse, fazem exercícios, e estão dispostas a consumir produtos do seu agrado, que os façam sentir-se bem além do conforto ao vestir. Sobre o mercado brasileiro idoso, Morsch (2015) afirma que $45 \%$ dos idosos encontram dificuldades para comprar produtos adequados para sua idade - percepção mais acentuada entre mulheres (47\%) e indivíduos entre 70 e 75 anos (51\%).

Dessa forma, sugere-se usar um método de design participativo para que os usuários estejam inseridos no processo de desenvolvimento dos produtos de moda, desde a detecção de problemas até a hora da criação. Trabalhar juntamente com o público, utilizando ferramentas do design participativo, seria uma forma de trazê-lo ao processo criativo e deixar que os próprios indivíduos manifestem seus desejos e contribuam para a geração de uma solução para um problema real.

No presente estudo, foram selecionadas idosas de 60 a 80 anos, sendo estas donas de casa, que se reúnem ao menos uma vez na semana para conversar e se distrair, saem com bastante frequência, de forma independente, e que fazem ao menos alguma atividade física e têm um dia movimentado. As usuárias estiveram presentes em todos os momentos e foram as responsáveis pelas decisões, cabendo à designer o papel de facilitadora do processo, conduzindo a aplicação das ferramentas, e apresentando a informação de moda como base para o desenvolvimento dos produtos. Como resultado, foram gerados produtos alinhados às necessidades de conforto e vestibilidade do público, mas também dosando informação de moda e tendências que as usuárias se mostraram dispostas a assimilar. 


\title{
20 CONSUMIDOR IDOSO
}

Dados do Instituto Brasileiro de Geografia e Estatística (IBGE, 2000) indicam um grande crescimento do índice de envelhecimento, o qual em 1950 era de 5,83 e em 2000 já era de 19,77. Segundo a empresa Innovare Pesquisa (2016), 18,5 milhões de pessoas no Brasil são aposentadas, com renda média de pelo menos um salário mínimo. Isso quer dizer que a população idosa possui uma fonte de renda própria. Entretanto, o estigma da aposentadoria contribui para uma imagem estereotipada de dependência e inatividade dessas pessoas. Para Martins e Rodrigues (2004, p. 253), "os estereótipos tornam-se inevitavelmente elementos impeditivos na procura de soluções precisas e de medidas adequadas, tornando-se urgente o combate a estas representações sociais gerontofóbicas".

O estereótipo de dependência do idoso ainda não é muito bem definido, pois não há um único nicho. Existem, sim, idosos que têm problemas de saúde, apresentam perda de visão, audição, dificuldades de locomoção e de cumprir tarefas do cotidiano, vivendo com baixa qualidade de vida. Por outro lado, também existem idosos que são independentes física e mentalmente, muitas vezes inseridos no mercado de trabalho, complementando a renda e exercendo papel importante na família (CAMARANO, 2004). Ainda, segundo Ballstaedt (2007, p. 11):

\begin{abstract}
Como perfil do consumidor idoso brasileiro, podemos observar o grande bolo que está inserido tanto os "velhinhos clássicos", aqueles que fazem tricô e jogam xadrez na praça, como outros que trabalham, viajam regularmente, fazem academia e consomem produtos e serviços altamente especializados e sofisticados. Esse segundo grupo surge como parte de um fenômeno do envelhecimento numa sociedade em que há uma oferta enorme de alternativas e tecnologias que oferecem qualidade e prolongamento de vida.
\end{abstract}

Dessa forma, hoje a "terceira idade" é um período da vida que apresenta novas compreensões e desafios, então, é importante desmistificar e compreender melhor quem são esses indivíduos e do que precisam.

Em um estudo realizado somente com indivíduos acima de 60 anos, Bacha, Strehlau e Perez (2006) buscaram chegar à compreensão do significado do termo "Terceira Idade" para o grupo pesquisado. Os autores concluíram que os termos que apresentaram maior concordância pelo público foram: velhice ativa, nova juventude, inutilidade, tempo de sabedoria, idade dos sentimentos, integração, tempo de resignação, isolamento e época da maturidade. A partir desse exemplo, pode-se notar que as pessoas acima de 60 anos atualmente 
não têm a mesma mentalidade e nem o mesmo comportamento de pessoas com essa idade a anos atrás.

O mercado para o público da terceira idade começou a ser pensado recentemente, e há espaço para que seja melhor explorado, tendo um olhar voltado para o indivíduo idoso com mais atenção. Segundo Gomes e Lüdorf (2009), com tantas alterações decorrentes do envelhecimento, a moda representa algo muito mais importante para os idosos que meramente a escolha de roupas. Uma moda adequada ao idoso, que leve em conta os aspectos funcionais, representa um importante fator a ser considerado, uma vez que a roupa adequada poderia representar ganhos não só na qualidade de vida do idoso, como na sua representação na sociedade.

Bernardo e Pepece (2014) fizeram um levantamento sobre as roupas adequadas para cada ocasião, entrevistando 10 senhoras de 70 a 75 anos, e constataram pontos relevantes, tais como: elas desejam encontrar peças diferentes, mas que sejam belas; procuram roupas nas quais que se sintam bem, e que demonstrem como se sentem; querem se sentir confortáveis e confiantes, sem estereótipos.

Dessa forma, cada vez mais se destaca a necessidade de investimento em produtos que atendam às necessidades desse público, pois são pessoas que tem algum tipo de renda para investir em produtos de moda que atendam à sua concepção de qualidade.

Existem marcas no mercado nacional que se dizem voltadas a esse segmento. Um exemplo é a Sharisma (2016), que, em seu site, declara ser a primeira loja do Brasil a oferecer roupas comuns e roupas adaptadas para idosos ou portadores de necessidades especiais. Entretanto, essas são roupas para algum momento de necessidade específica desse usuário, como uma tecnologia assistiva, e não produtos de moda para o idoso atual, que está ativo e está inserido na sociedade. Outras marcas também se dizem voltadas para a terceira idade, como Loja do Avô e a Daruni Healthcare, mas estas são lojas igualmente voltadas a necessidades específicas desse usuário, oferecendo acessórios para suporte em alguma dificuldade. Internacionalmente, um exemplo positivo é a cidade de Grossräschen, na Alemanha que, pensando na grande porcentagem de idosos entre seus habitantes, criou uma loja totalmente voltada à terceira idade, projetada para acomodar esses indivíduos (JAMES, 2007).

Visto que esse é um público com pouca voz no mercado, especialmente no de moda, sugere-se usar o método de design participativo para que os usuários estejam inseridos no processo de desenvolvimento do produto e sejam efetivamente ouvidos. Essa seria uma forma de traze-los para o processo criativo, deixando que os próprios indivíduos expressem quais são seus reais problemas, bem como o que realmente lhes agrada. 


\title{
3 DESIGN PARTICIPATIVO
}

O Design Participativo é um dos diversos métodos de criação do design que tem a função de valorizar a participação dos usuários durante o processo de desenvolvimento dos produtos, com a utilização de ferramentas que estimulem os usuários a se expressarem e mostrarem quais são suas carências. Esse método traz o usuário-alvo para todas as etapas do processo, desde a discussão dos problemas até a criação da solução (HEEMAN, 2008).

Paizan e Mellar (2011, p. 3) comentam que:

\begin{abstract}
O Design Participativo surgiu da discussão de como práticas de design democráticas poderiam ser introduzidas no setor industrial. Como aponta Ehn (1992), os países Escandinavos na década de 1960, o berço do DP, compartilhavam elementos que contribuíam para a discussão sobre democracia como, por exemplo, uma força de trabalho com excelente formação e homogênea, um alto nível de sindicalização, sindicatos fortes ligadas a grandes partidos democráticos.
\end{abstract}

Essa técnica foi criada para trazer todas as partes envolvidas em um determinado problema para as discussões, de forma a relatar os problemas reais vividos diariamente, sem suposições, dando novas e mais claras visões sobre o assunto.

Existe também o Design Colaborativo que, para Roldão (2007, p. 27), é "um processo de trabalho articulado e pensado em conjunto, que permite alcançar melhor os resultados visados, com base no enriquecimento trazido pela interação dinâmica de vários saberes específicos e de vários processos cognitivos em colaboração." Cabe ressaltar que o design participativo e o colaborativo são duas formas de trabalho diferentes. Esta última abordagem traz diversos profissionais trabalhando sobre algum problema de design, porém, desenvolve a solução sem o contato direto com o público.

\subsection{Ferramentas para o design participativo}

Dentro do método do design participativo, existem inúmeras ferramentas que podem contribuir para facilitar a participação do usuário no processo. Algumas dessas ferramentas, adotadas no presente estudo, são: imersão em contexto, focus group, e jogo de cartas. 
A imersão em contexto é uma técnica que analisa o cotidiano dos indivíduos para entender quem são, o que pensam e dizem quando estão mais à vontade, e como se comportam em outros lugares (IDEO, 2015).

Já o focus group, ou grupo focal, consiste em um mediador que coloca algumas questões e temas na conversa de modo informal e descontraído em um pequeno grupo de pessoas. Para Gaskel e Bauer (2002, p.75) "O objetivo do grupo focal e estimular os participantes a falar e a reagir aquilo que outras pessoas no grupo dizem. É uma interação social mais autentica".

Por fim, o jogo de cartas, segundo Frisoni e Steil (2005, p. 2), "é uma técnica comumente utilizada para descobrir-se o modelo mental que os usuários têm de determinado espaço de informação." Para Spencer (2004) e Quintas (2016) o jogo de cartas pode ser feito de até três maneiras: (a) Tipo aberto, no qual os participantes recebem as cartas sem categorias, e eles próprios elaboram as categorias e colocam os cartões nelas. É um método útil para visualizar não só o objeto que foi classificado, mas também qual o padrão foi utilizado; (b) Tipo fechado, no qual já existem categorias predeterminadas e cabe aos participantes analisar e posicionar as cartas. O método permite observar se o indivíduo realmente identificou a categoria. (c) Tipo híbrido, no qual alguns participantes recebem as categorias e outros não. Por meio desse método é possível analisar os termos utilizados pelos participantes e pelos próprios pesquisadores.

Por meio dessas ferramentas, é possível aproximar o usuário final de todas as etapas do processo de design, esclarecendo o que realmente importa ao usuário, não no que o designer acredita que seja importante para o outro. Dessa forma, a equipe de design tem acesso a informações que seriam difíceis de se obter sem o método, pelo fato de não ter uma real experiência com o usuário.

\section{MÉTODO}

O estudo investigou a possibilidade de adaptação das ferramentas do design participativo para o desenvolvimento de produtos de moda para o público feminino da terceira idade. A pesquisadora optou por selecionar um grupo de senhoras que já faziam parte de seu círculo de convivência, para que pudesse ter contato direto com suas rotinas, e de modo que elas se sentissem confortáveis com a participação.

Assim, a primeira ação tomada no desenvolvimento foi incorporar a ferramenta de imersão em contexto, ou seja, participar do dia-a-dia do público 
buscando uma visão real de quem são e como se comportam. Essas informações facilitam a contextualização da pesquisadora e, consequentemente, o processo de empatia.

Num segundo momento, foi utilizada a ferramenta jogo de cartas para verificar a aceitação das tendências de moda por parte das usuárias. As tendências de moda muitas vezes passam despercebidas para o público leigo, que vê as peças nas vitrines e nas lojas, mas não entende ou mesmo se importa como elas chegaram ali -simplesmente gostam e compram, ou não. Tal comportamento é muito comum no público da terceira idade, em especial, porque a moda não faz parte de seu cotidiano. Dessa forma, o processo consistiu em filtrar as tendências - mapeadas previamente pela pesquisadora -, apresentando-as já explicitas em peças comerciais, com o objetivo de analisar o nível de aceitação delas.

A etapa seguinte, de criação, foi iniciada desenvolvendo previamente o mix de coleção, com base nas peças presentes e quantidades das mesmas no guarda-roupa delas. Após essa tarefa, a pesquisadora atuou somente como mediadora no focus group, registrando o que as participantes escolhiam.

Esse registro foi posteriormente avaliado pela pesquisadora - a partir de seu conhecimento específico em design - para identificar possíveis dificuldades técnicas e, ainda, acrescentar mais informação de moda nos produtos. A avaliação dessas alterações ficou novamente a cargo do público, que contribuiu com mais ideias para se chegar ao resultado final, apresentado a seguir.

\section{RESULTADOS}

Após a imersão em contexto, foi possível observar que o grupo que participou do estudo é composto por quatro senhoras de 60 a 80 anos, donas de casa, independentes tanto socialmente quanto financeiramente, que não mantêm o hábito de praticar atividades físicas específicas, mas estão sempre em movimento e saem sozinhas com bastante frequência. Se reúnem ao menos uma vez na semana para conversar, tomar chimarrão e se distrair. Com essa observação ativa, foi possível compreender melhor o estilo de vida das usuárias, o que trouxe insights e parâmetros para o desenvolvimento.

O próximo passo tratou das tendências, utilizando o jogo de cartas tipo aberto. As tendências selecionadas foram previamente mapeadas pela pesquisadora e filtradas para que pudessem ser apresentadas já explicitas em peças comerciais. Num primeiro momento, as participantes afirmaram se usariam ou não as peças; num segundo momento, apontaram se preferiam uma 
ou outra opção; posteriormente, eram apresentados a elas alguns aviamentos, para que opinassem sobre eles; finalmente, elas foram questionadas de forma a chegar a uma cartela de cores preliminar.

Essa etapa do processo foi de descobertas e quebra de paradigmas - conforme as participantes respondiam, percebeu-se que elas aceitavam as tendências de uma forma positiva, demonstrando interesse ao tentar entender do que se tratava, e dispostas a experimentá-las. A visualização de um produto final, nesse momento, não foi possível, pois ainda não se falava das roupas das participantes ou sobre o que elas gostariam. Entretanto, a abertura das participantes a visualizar as tendências em si mesmas mostrou que estavam dispostas a tentar algo novo. Algumas respostas foram unânimes, outras ficaram mais divididas. $O$ quadro 1 traz uma síntese dos resultados obtidos nessa primeira fase:

Quadro 1 - Aceitação de tendências a partir do jogo de cartas.

\begin{tabular}{|c|c|c|c|c|c|}
\hline TENDÊNCIA & ACEITAÇÃO & ISSO OU AQUILO & ACEITAÇÃO & AVIAMENTOS & ACEITAÇÃO \\
\hline Slip dress & $25 \%$ & Reta x skinny & $100 \%$ reta & Zíper metal & $100 \%$ \\
\hline Top com babado & $100 \%$ & Pantalona x pantacourt & $\begin{array}{c}50 \% \text { pantalona / } 50 \% \\
\text { pantacourt }\end{array}$ & Botão & $100 \%$ \\
\hline Túnica & $100 \%$ & $\begin{array}{c}\text { Calça pescador } x \\
\text { bermuda }\end{array}$ & $100 \%$ calça pescador & Renda & $25 \%$ \\
\hline Maxi-colete & $100 \%$ & Vestido $\times$ saia & $100 \%$ vestido & Patch & $100 \%$ \\
\hline Pantalona & $75 \%$ & $\begin{array}{l}\text { Vestido curto } \mathrm{x} \text { médio } \mathrm{x} \\
\text { longo }\end{array}$ & $100 \%$ médio & Spikes & $100 \%$ \\
\hline \multirow[t]{5}{*}{ Ombro a ombro } & $0 \%$ & Manga curta $\times$ regata & $100 \%$ manga curta & Pedras & $100 \%$ \\
\hline & & $\begin{array}{c}\text { Estampado } \times \text { sem } \\
\text { estampa }\end{array}$ & $100 \%$ estampado & Corrente & $0 \%$ \\
\hline & & Tons claros $\mathrm{x}$ escuros & $100 \%$ escuros & Franja & $0 \%$ \\
\hline & & Estampa local $x$ corrida & $100 \%$ corrida & & \\
\hline & & $\begin{array}{c}\text { Floral } \mathrm{x} \text { animal } \mathrm{x} \\
\text { geométrico }\end{array}$ & $100 \%$ animal & & \\
\hline
\end{tabular}

Fonte: As autoras.

A fase de criação foi iniciada a partir do mix de coleção já desenvolvido, conforme descrito no método. O processo criativo foi feito no modelo focus group, no qual a pesquisadora atuou apenas como mediadora, desenhando conforme instruções das participantes. O processo foi construtivo, como um quebra-cabeça: ao desenhar a camisa, elas escolhiam qual tipo gola, quantos botões, se haveriam detalhes como pala, etc.

Essa foi a fase mais demorada do processo, visivelmente cansativa para as participantes, pois cada item foi discutido e avaliado em detalhes. Inicialmente, o processo foi um pouco mais lento, até que elas entendessem a dinâmica proposta. Mas, conforme desenvolveram-se as atividades, elas sentiram-se mais confortáveis para criar e demonstraram engajamento. O processo foi, de modo geral, sempre descontraído, esclarecendo que não há resposta certa ou errada, uma preocupação constante delas.

Em diversos momentos, as participantes lembravam-se de modelos que viram na rua ou na televisão, peças que elas mesmas tinham e gostavam, 
e trocavam ideias sobre detalhes que não conheciam e as agradaram. Foi um processo realmente participativo, pois as ideias se complementavam. Aos poucos, as participantes perderam a tensão inicial por se acharem demasiadamente responsáveis, percebendo que tudo aquilo poderia ser um momento lúdico, uma oportunidade de colocarem tudo que gostariam de ver em uma peça projetada por elas e para elas. Um detalhe, muitas vezes, trazia consigo uma história que elas compartilhavam durante o momento de criação, lembrando de situações nas quais as outras também se viam, fazendo da atividade um momento de troca.

Em seguida, a pesquisadora fez uma análise peça a peça, agora sem a presença das participantes, de modo a verificar a viabilidade de confecção e as possibilidades de acrescentar ainda mais informação de moda aos produtos. A próxima etapa consistiu, então, em expor às participantes as questões de vestibilidade e viabilidade detectadas, bem como sugerir pequenas modificações, que deveriam ser aprovadas pelas participantes. Teve-se um cuidado para que essa conversa tivesse caráter neutro, evitando induzi-las a decisões que não lhes agradassem de fato.

Os modelos foram, assim refinados e representados em forma de croqui. Houve também uma preocupação em representar o público de maneira real no desenho de moda, para que as participantes pudessem de fato visualizarem-se na representação. O resultado está representado a seguir, nas figuras 1, 2, 3 e 4.

\section{Figura 1 - Peças criadas.}
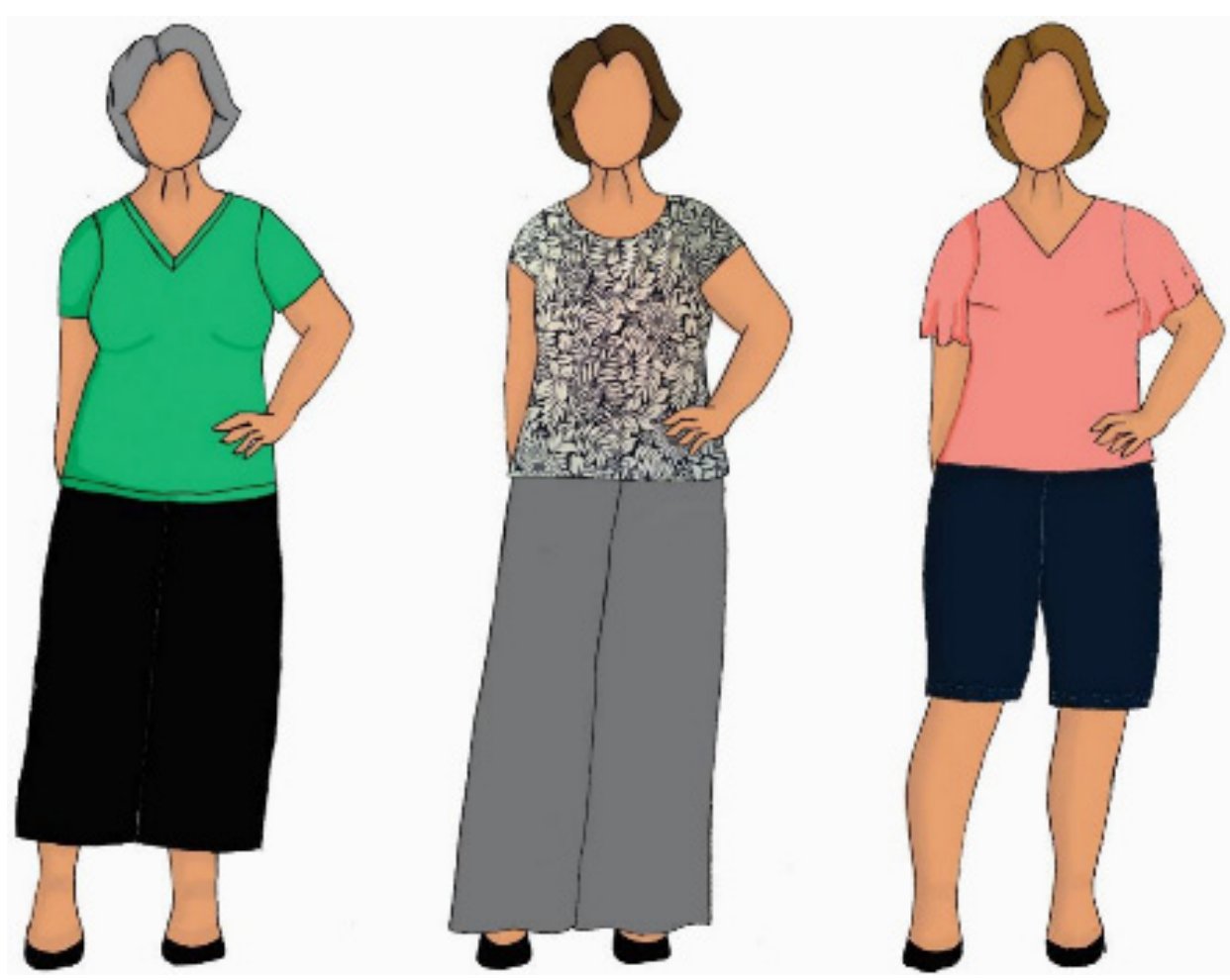

Fonte: As autoras. 
Figura 2 - Peças criadas.
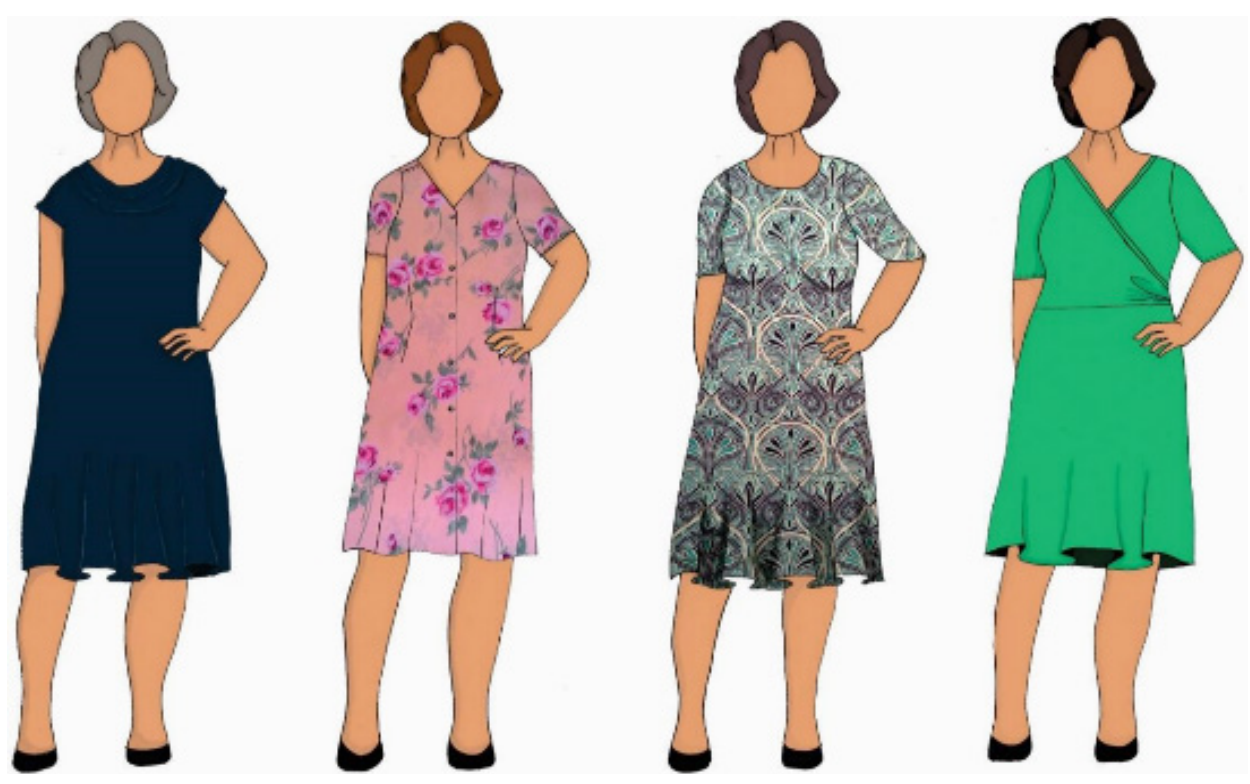

Fonte: As autoras.

Figura 3 - Peças criadas.

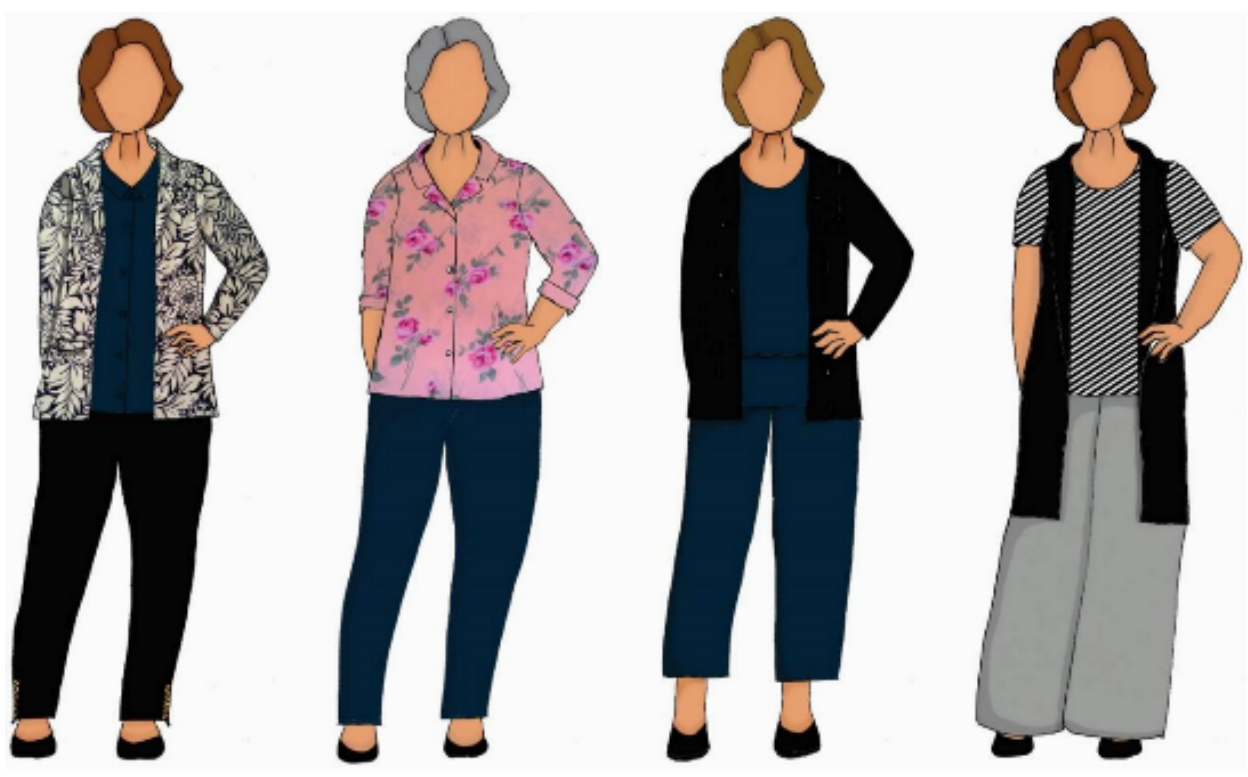

Fonte: As autoras. 
Figura 4 - Peças criadas.
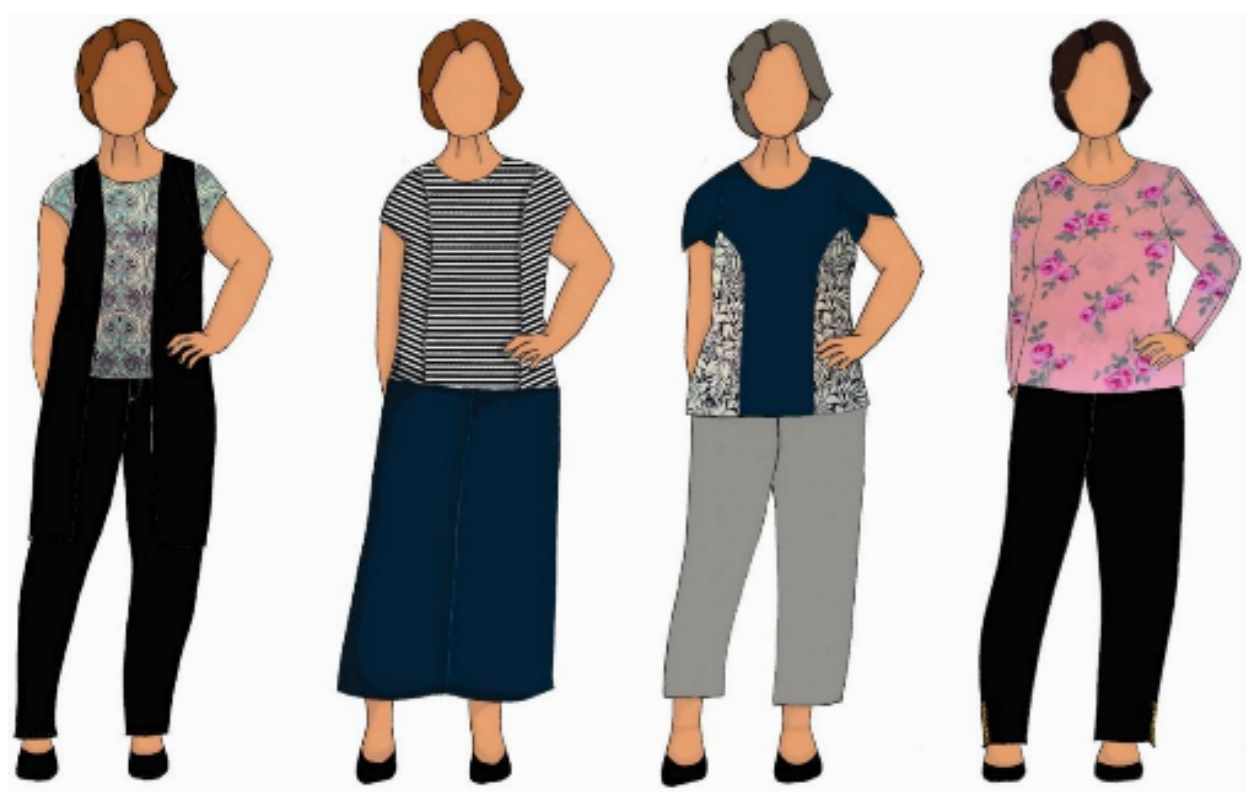

Fonte: As autoras.

Ao todo, foram concebidos 15 looks. Quatro deles foram confeccionados, conforme apresentado na figura 5 , e vestidos pelas próprias participantes para avaliação.

Figura 5 - Participantes do projeto vestindo as peças projetadas.

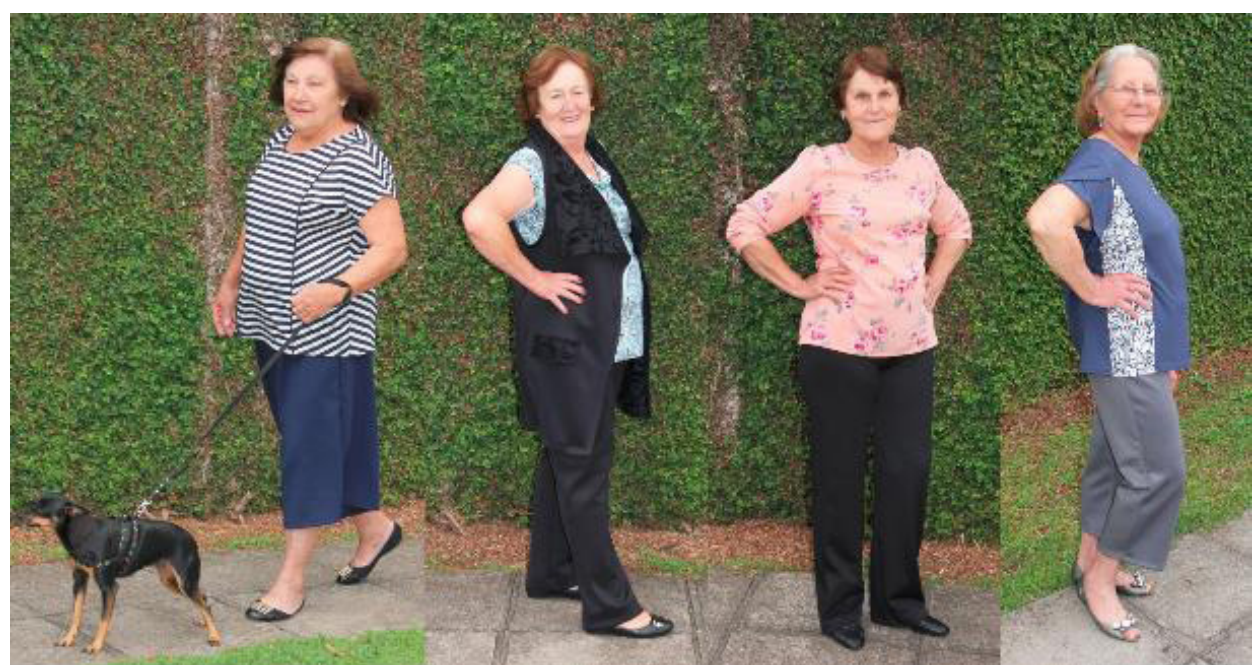

Fonte: A autora.

A pantacourt, o maxi colete com mistura de texturas, a blusa floral com manga franzida, a blusa com estampa gráfica de listras em preto e branco esses são exemplos de peças com informação de moda que, a princípio, poderiam estar presentes também em coleções para mulheres mais jovens. Assim, os modelos confeccionados representam como tendências, detalhes de modelagem e aviamentação podem estar presentes em produtos projetados para o público da terceira idade, desde que dosados pelos parâmetros das próprias usuárias. 


\section{CONSIDERAC̣ÕES FINAIS}

Após experienciar um processo de desenvolvimento imerso em contexto, percebe-se a falta de um olhar mais sensível, por parte dos designers, sobre o público idoso. É necessária uma melhor compreensão sobre o conceito de terceira idade, sobre o envelhecer e suas reais necessidades.

O design participativo pressupõe que os usuários têm capacidade de entendimento e propriedade sobre suas próprias necessidades e desejos, independentemente de seu conhecimento técnico, o que se apresentou verdadeiro nessa pesquisa. O processo gerou resultados significativos, apontando que pequenas doses de informação de moda - por exemplo, tendências, cores mais vivas e detalhes diferenciados - podem ser aceitas por esse público, geralmente estigmatizado como conservador.

Assim, conclui-se que o design participativo pode ser aplicado à moda, principalmente no que diz respeito à investigação de públicos ainda pouco explorados ou estereotipados. As informações únicas obtidas durante o processo contribuem para a geração de produtos com maior aceitação, pelo fato de o usuário se reconhecer no produto, e que também resolvam problemas reais, diretamente ligados ao dia-a-dia do público.

\section{REFERÊNCIAS}

BACHA, Maria de Lourdes; STREHLAU, Vivian lara; PEREZ, Gilberto. A compreensão do significado do termo terceira idade pela terceira idade em São Paulo. 2006. Disponível em: <http://www.anpad.org.br/admin/pdf/ema2006mktb-391.pdf>. Acesso em: 4 jun. 2016.

BALLSTAEDT, Ana Luiza Maia Pederneiras. Comportamento e estilo de vida da população idosa e seu poder de consumo. In: ENCUENTRO LATINOAMERICANO DE DISEÑO, 2., 2007, Buenos Aires. Anales... Buenos Aires, 2007. Disponível em: <http://fido.palermo.edu/servicios_dyc/ encuentro2007/02_auspicios_publicaciones/actas_diseno/articulos_pdf/A004. pdf>. Acesso em: 4 jun. 2016.

BERNARDO, Patricia; PEPECE, Olga Maria Coutinho. Moda para a terceira idade: a roupa adequada para cada ocasião. Projética, Londrina, v. 5, n. 1, p. 57-74, 2014. BRASIL. Secretaria de Direitos Humanos. Dados sobre o envelhecimento no Brasil. Disponível em: <http://www.sdh.gov.br/assuntos/pessoa-idosa/dadosestatisticos/DadossobreoenvelhecimentonoBrasil.pdf>. Acesso em 17 maio 2016. 
CAMARANO, Ana Amélia. Os novos idosos brasileiros: muito além dos 60? Rio de Janeiro: IPEA, 2004.

FRISONI, Bianca Cappucci; STEIL, Viviane. Como estruturar melhor a área de contato com o usuário? a utilização da técnica de Card Sorting para desenvolver a estrutura do website do núcleo de inovação em design da cadeia têxtil. In: CONGRESSO INTERNACIONAL DE ERGONOMIA E USABILIDADE, DESIGN DE INTERFACES E INTERAÇÃO HUMANO-COMPUTADOR, 5., 2005, Rio de Janeiro. Anais... Rio de Janeiro: USIHC, 2005.

GASKEL, George; BAUER, Martin W. (Org.). Pesquisa qualitativa com texto, imagem e som: um manual prático. Petrópolis: Vozes, 2002.

GOMES, Murilo Cabral; LÜDORF, Silvia M. Agatti. Idoso, moda e sedentarismo: possíveis relações. Revista Eletrônica da Escola de Educação Física e Desportos, Rio de Janeiro, n. 2, p. 158-167, 2009.

HERMAN, M. Bartleby, o escriturário: uma história de wall street. São Paulo: L Pm Pocket, 2008.

IBGE. Censo demográfico 1950/2000. Disponível em: <http:// seriesestatisticas.ibge.gov.br/series.aspx?vcodigo $=$ CD88>. Acesso em: 4 jun. 2016.

IDEO. Human-centered design toolkit. 2015. Disponível em: <https://www. ideo.com/post/design-kit>. Acesso em: 16 jun. 2016.

INNOVARE PESQUISA. Os aposentados brasileiros. 2016. Disponível em: <http://www.innovarepesquisa.com.br/blog/os-aposentados-brasileiros/>. Acesso em: 16 jun. 2016.

JAMES, Kyle. Na Alemanha que envelhece, florescem lojas para a terceira idade. 2007. Disponível em: <http://www.dw.com/pt/na-alemanha-queenvelhece-florescem-lojas-para-aterceira-idade/a-2670021>. Acesso em: 5 jun. 2016.

MARTINS, Rosa Maria Lopes; RODRIGUES, Maria de Lourdes Martins. Estereótipos sobre idosos: uma representação social gerontofóbica. Millenium: educação, ciência e tecnologia, Viseu, p. 249-254, 2004. Disponível em: <http://www.ipv.pt/millenium/Millenium29/32.pdf>. Acesso em: 13 mar. 2017.

MORSCH, Marco. Novo consumidor idoso: um filão de oportunidades. 2015. Disponível em: <http://www.administradores.com.br/artigos/negocios/novoconsumidor-idoso-umfilao-de-oportunidades/89944/>. Acesso em: 24 jun. 2016.

PAIZAN, Delfina Cristina; MELLAR, Harvey. Envolvendo os alunos no design de tecnologia educacional: aprendendo com o design participativo. In: SIMPÓSIO ESTUDOS LINGUÍSTICOS E LITERÁRIOS: SABERES E EXPRESSÕES GLOBAIS, 2011. Anais... Foz do Iguaçu: Unoeste, 2011.

QUINTAS, Rodrigo Karam. Ferramentas de co-design voltadas a moradores de habitação de interesse social. 2016. Dissertação (Mestrado em Design) Universidade Federal do Paraná, Curitiba, 2016. 
ROLDÃO, Maria do Céu. Colaborar é preciso: questões de qualidade e eficácia no trabalho dos professores. Revista Noesis, Lisboa, n. 71, p. 24-29, 2007.

SPENCER, Donna. Card sorting: a definitive guide. 2004. Disponível em: <http://boxesandarrows.com/card-sorting-a-definitive-guide/>. Acesso em: 12 maio 2016. 